\title{
Signaling Networks that Regulate Cell Migration
}

\section{Peter Devreotes ${ }^{1}$ and Alan Rick Horwitz ${ }^{2}$}

${ }^{1}$ Department of Cell Biology, Johns Hopkins University School of Medicine, Baltimore, Maryland 21205

${ }^{2}$ Department of Cell Biology, University of Virginia School of Medicine, Charlottesville, Virginia 22908

Correspondence: pnd@jhmi.edu a005959

\section{SUMMARY}

Stimuli that promote cell migration, such as chemokines, cytokines, and growth factors in metazoans and cyclic AMP in Dictyostelium, activate signaling pathways that control organization of the actin cytoskeleton and adhesion complexes. The Rho-family GTPases are a key convergence point of these pathways. Their effectors include actin regulators such as formins, members of the WASP/WAVE family and the Arp2 / 3 complex, and the myosin II motor protein. Pathways that link to the Rho GTPases include Ras GTPases, TorC2, and PI3K. Many of the molecules involved form gradients within cells, which define the front and rear of migrating cells, and are also established in related cellular behaviors such as neuronal growth cone extension and cytokinesis. The signaling molecules that regulate migration can be integrated to provide a model of network function. The network displays biochemical excitability seen as spontaneous waves of activation that propagate along the cell cortex. These events coordinate cell movement and can be biased by external cues to bring about directed migration.

\section{Outline}

\section{Introduction}

2 The migration machinery

3 Migration signaling networks
4 Biased excitable biochemical networks in chemotaxis

5 Concluding remarks

References

Editors: Lewis Cantley, Tony Hunter, Richard Sever, and Jeremy Thorner

Additional Perspectives on Signal Transduction available at www.cshperspectives.org

Copyright $\odot 2015$ Cold Spring Harbor Laboratory Press; all rights reserved; doi: 10.1101/cshperspect.a005959 


\section{INTRODUCTION}

Cell migration plays a pivotal role in a wide variety of phenomena throughout phylogeny (Trinkaus 1969; Ridley et al. 2003; Lee et al. 2005; Cai et al. 2010). In the amoeba Dictyostelium, it functions in nutrient seeking, cell-cell aggregation, and the morphogenesis of multicellular structures. In metazoans, cells migrate both throughout embryogenesis and in the adult. In early developmental events, such as gastrulation or dorsal closure, large cell sheets migrate and fold; at later stages, precursor cells that reside in the neural crest, somites, brain ventricles, and other stem cell regions leave epithelial sheets and migrate to their target destinations. In the adult, cell migrations are critical for immune cell trafficking, wound healing, and stem cell homing, among other processes. A closely related phenomenon is the directed growth of specialized cellular extensions (e.g., yeast mating "shmoos" [Slessareva and Dohlman 2006], pollen tubes [Takeuchi and Higashiyama 2011], and the dendrites, axons, and spines of neurons [Tada and Sheng 2006; Geraldo and Gordon-Weeks 2009]).

Most migrating cells and cellular extensions have an internal compass that enables them to sense and move along gradients of soluble attractants and repellents, a process referred to as chemotaxis (Devreotes and Janetopoulos 2003). Many chemoattractants act through G-proteincoupled receptors (GPCRs). Examples include cAMP acting on cAMP receptors in Dictyostelium and chemokines such as SDF1 acting on chemokine receptors in metazoans. Growth factors acting on receptor tyrosine kinases and cytokines such as transforming growth factor $\beta$ (TGF $\beta$ ) also function as chemoattractants. Like migrating cells, the growth of axons can be guided by a series of extracellular protein attractants and repellents (e.g., nephrins). Cells can also be guided by gradients of immobilized signaling molecules (haplotaxis), substrate rigidity (durotaxis), electric fields (galvanotaxis), and shear force (mechanotaxis). Importantly, many diseases involve defective or unregulated cell migration or protrusive growth (Ridley et al. 2003). For example, tumor invasion and metastasis occur as a consequence of the movement of both individual cells and large collectives (Friedl and Gilmour 2009; Friedl and Alexander 2011), arthritis and asthma result from excessive migration of inflammatory cells (Montoya et al. 2002; Vicente-Manzanares et al. 2002), and several cognitive disorders are accompanied by abnormal neuronal extensions (Newey et al. 2005; van Galen and Ramakers 2005).

Cell migration requires coordination of cytoskeletal dynamics and reorganization, cell adhesion, and signal transduction, and takes a variety of forms (see Box 1) (Lauffenburger and Horwitz 1996; Mitchison and Cramer 1996; Ridley et al. 2003). Here, we first examine the machinery that drives migration - the actin cytoskeleton, cell adhesions, and their regulators. We then discuss signaling networks that control the migration machinery, starting with those closest to the cytoskeleton then adding upstream components. Finally, we address how chemotactic cues regulate motility. There are, of course, other kinds of motility, such as sperm and cilial motility, but they use microtubulebased mechanisms and are not addressed here.

\section{THE MIGRATION MACHINERY}

\subsection{Actin Polymerization and Myosin-Mediated Contraction}

Polymerization of globular $(\mathrm{G})$ actin monomers to form filamentous (F) actin is critical for cell migration (Pollard

\section{BOX 1. THE SPECTRUM OF CELL MIGRATION BEHAVIORS}

Cells can move in a variety of different ways, depending on the differentiated cell type, the surrounding environment, and the organism. The "mesenchymal" migration of fibroblasts, which have large actin filament bundles and prominent adhesions, is slow, for example. Similarly, keratocytes have an actin-rich lamellipodium, but these move more rapidly than fibroblasts. The amoeboid movements of neutrophils and Dictyostelium are instead characterized by the presence of rapid, efficient pseudopodial extensions and low adhesion. Cells such as primordial germ cells and some leukocytes and tumor cells can move by "blebbing," a contraction-mediated squeezing from the rear that produces a protrusion in regions lacking highly organized actomyosin filaments (Charras and Paluch 2008; Friedl and Wolf 2010; Schmidt and Friedl
2010). These migration modes are related, residing along a continuum, and can interconvert depending on cell state, the extracellular environment, and the relative activation of different pathways; but they are distinct from the "swimming" driven by beating of flagella or cilia that is observed in some cells. Migration can result in the movement of single cells, small collectives, or large sheets. It can also occur over a variety of substrata that include other cells and extracellular matrix components. Tumor cells can adapt to their environment by using diverse migration modes that include mesenchymal, amoeboid, and blebbing modes. They can also use specialized adhesion structures like invadopodia, which localize proteolytic activity that degrades the local matrix (Linder et al. 2011). 
and Borisy 2003; Ridley 2011). It produces oriented filaments that grow at the so-called barbed end and push the front (the leading edge) of the cell forward, driving cell migration. In cells that migrate by blebbing, actin stabilizes the blebs following their protrusion (Charras and Paluch 2008; Fackler and Grosse 2008). Actin filaments arise and grow through a complex but well-understood process (Fig. $1)$. Actin nucleation and polymerization are regulated by formins (e.g., mDia1 and mDia2) and the Arp2/3 complex (Insall and Machesky 2009; Chesarone et al. 2010; Ridley 2011). The formins nucleate and regulate the growth of linear actin filaments (Goode and Eck 2007; Paul and Pol-

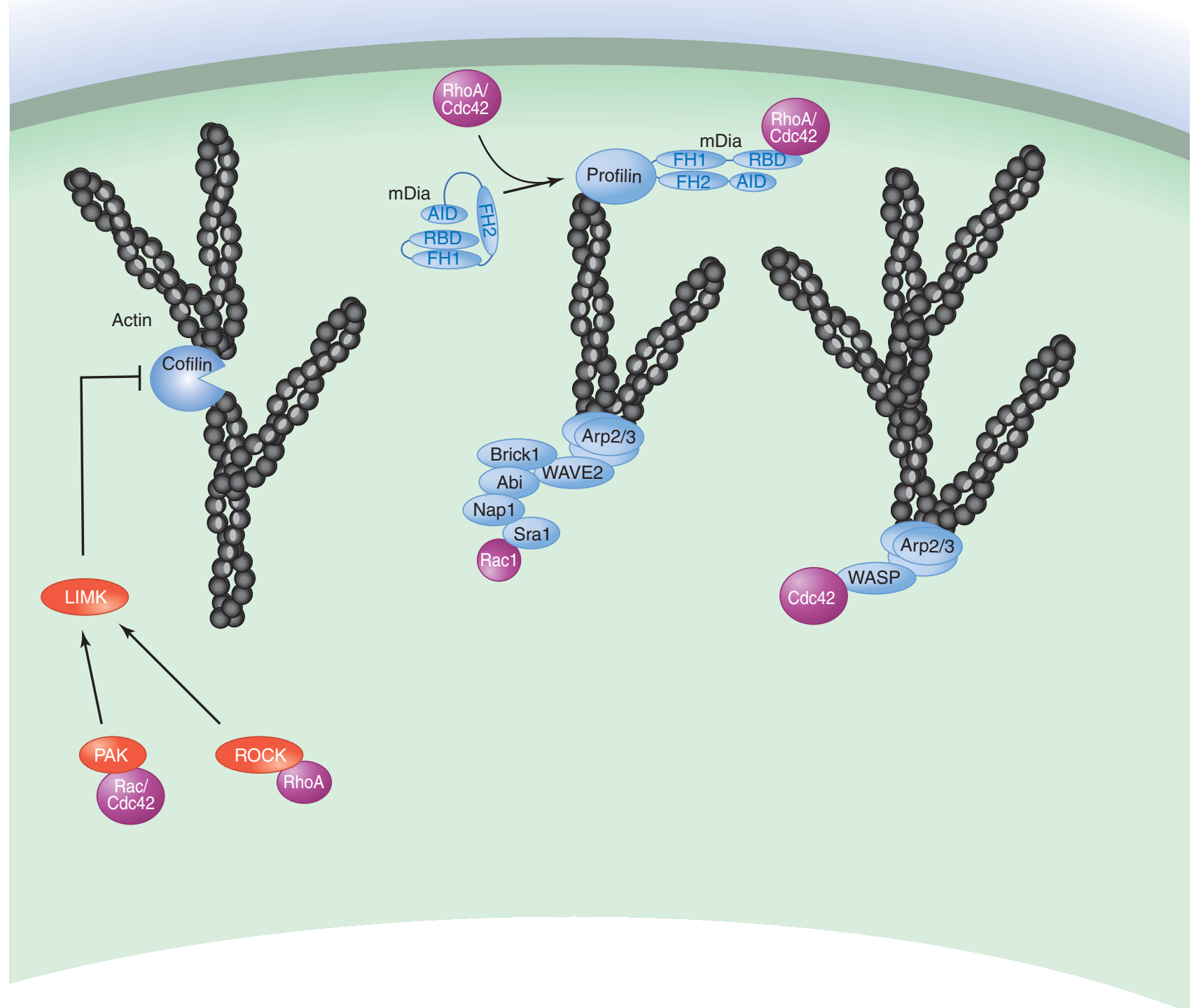

Figure 1. Regulation of actin dynamics by formins and Arp2/3 in cellular protrusions. The Rho GTPases Rac, RhoA, and Cdc42 regulate actin dynamics at the leading edge via their effects on the activities of formins (mDia), Arp2/3 complex, and LIM kinase (LIMK). Arp2/3 nucleates actin branches that are seen in broad protrusions. Its activity is regulated by Cdc42 and Rac1, which act on WASP/WAVE-containing protein complexes. Rac and Cdc42 also act on PAK, which phosphorylates LIM kinase, which in turn regulates cofilin, a severing protein. Finally, RhoA acts on mDia1 and Cdc42 acts on mDia2 to promote actin polymerization using a processive capping mechanism. RhoA also activates profilin, which binds to actin monomers and increases the rate of polymerization. These GTPases are activated in a clear temporal sequence near the leading edge (Machacek et al. 2009). AID, autoinhibitory domain; $\mathrm{FH}$, formin homology domains; RBD, Rho-GTPase-binding domain. 
lard 2009). These processive capping proteins sequentially add actin monomers while remaining weakly bound to the rapidly growing (barbed) end of the filaments, a process termed processive elongation. The Arp $2 / 3$ complex nucleates branches from existing actin filaments at a $70^{\circ}$ angle and thereby produces the dendritic actin network that is prominent near the leading edge of broad protrusions and appears to stabilize them (Insall and Machesky 2009).

These mediators of actin branching and polymerization are highly regulated. In fibroblasts and many other cells, mDial and mDia2 are regulated by the Rho-family small GTPases RhoA and Cdc42, respectively, which relieve an autoinhibitory state. Two other proteins, ABI1 and G $\alpha 12$ / 13 , appear to direct mDial to actin filaments and adhesions. The Arp2/3 complex contains six subunits, including two actin-related proteins, Arp2 and Arp3, which nucleate new actin filaments by binding to the side of existing filaments. WASP family members (WAVE [also known as Scar] and the WASPs) are targets of the Rhofamily GTPases Rac1 (WAVE) and Cdc42 (WASP) and in turn interact with the Arp2/3 complex and regulate its activity (Pollitt and Insall 2009; Padrick and Rosen 2010).

Actin filaments are capped at the barbed end by capping proteins, which inhibits depolymerization and thereby stabilizes them. Anticapping proteins of the Mena/Vasp family, in turn, antagonize capping proteins and thereby regulate capping (Krause et al. 2003; Bear and Gertler 2009). Cofilin is another major regulator of actin filament stability that severs actin filaments; it also binds to G-actin, increasing the off-rate of actin monomers at the pointed (nonpolymerizing) end (Condeelis 2001; Bamburg and Bernstein 2008). LIM kinase, which is activated by Cdc42 and Rac1, stimulates cofilin activity by phosphorylation. LIM kinase is itself regulated by Cdc42 and Rac1, which act via the kinase PAK (Yamaguchi and Condeelis 2007; Bamburg and Bernstein 2008). Finally, profilin binds to actin monomers and increases the polymerization rate.

Contraction forces generated by myosin II motor proteins (Bugyi and Carlier 2010) are coordinated with actin polymerization at the leading edge and have several roles in migration (Small and Resch 2005; Vicente-Manzanares et al. 2009). First, in fibroblasts and epithelial cells, myosin II promotes retrograde movement of actin filaments away from the zone of active actin polymerization in the lamellipodium. This retrograde flow essentially subtracts from actin polymerization at the leading edge and can reduce the net protrusion rate (Ponti et al. 2004). The forces from both retrograde flow and actin polymerization can be "shunted" to the substratum via integrin-based adhesions linked to actin filaments (Mitchison and Kirschner 1988; Jay 2000). This shunting inhibits retrograde flow and enhances the protrusion rate, because the full force of actin polymer- ization acts at adhesions and the membrane at the leading edge. However, the transmission of force from actin through adhesions to the substratum is not always complete and can lead to varying rates of retrograde flow (Brown et al. 2006; Hu et al. 2007; Wang 2007; Chen et al. 2012). Second, the pressure from myosin-mediated contractions in the rear and sides can produce blebs in regions depleted of actomyosin filaments (Charras and Paluch 2008). In cells that move by blebbing, myosin-based contraction alone drives migration; however, the blebs are stabilized by the formation of a dendritic actin meshwork.

Myosin II activity is regulated by phosphorylation of myosin's regulatory light chain (RLC), and its assembly into filaments is regulated by phosphorylation in the tail region of the heavy chain (Vicente-Manzanares et al. 2009). A number of kinases can phosphorylate the RLC. Among the best studied are myosin light-chain kinase (MLCK) and Rho-associated protein kinase (ROCK); myosin phosphatase hydrolyzes the phosphate. In contrast to RLC regulation, the kinases regulating filament assembly are not well understood (Vicente-Manzanares et al. 2009).

\subsection{Adhesion}

Adhesion to the substrate is common to most migrating cells. Integrin-mediated adhesions are the best studied (Hynes 2002). The integrins are a large family of heterodimeric transmembrane receptors that link to actin via a specialized set of molecules that include talin, vinculin, and $\alpha$-actinin. The adhesions in which these components reside are large assemblies containing $>150$ different molecules that mediate intracellular signaling in addition to adhesion to proteins in the extracellular matrix, such as fibronectin and laminin (Zaidel-Bar et al. 2007; Parsons et al. 2010; Zaidel-Bar and Geiger 2010). The affinity of integrins is regulated by the binding of talin and kindlin, cytoplasmic proteins that bind directly to the cytoplasmic domain of the integrin $\beta$ subunit, and also by phosphatidylinositol 4,5-bisphosphate $\left(\mathrm{PIP}_{2}\right)$ and other adhesionassociated molecules (Moser et al. 2009; Shattil et al. 2010).

Adhesions serve both as traction points and as signaling centers during cell migration (Parsons et al. 2010). As traction points, they transmit forces to the substrate so that actin polymerization causes protrusion at the cell front. These traction points are released at the cell rear as it retracts and the cell moves forward. Although this release is efficient in some cells and substrates, it is not in others and can be rate limiting for migration (Lauffenburger and Horwitz 1996). Thus, there is an optimum strength of attachment that allows sufficient adhesion for traction at the cell front and yet allows for efficient release at the rear (Palecek et al. 1997). As signaling centers, adhesions in protrusions 
regulate actin polymerization and myosin II activity through Rho-family GTPases (Parsons et al. 2010). Although adhesions can vary considerably in size, location, and presumably function, they have not yet been classified clearly and meaningfully based on differences in composition and function. Adhesions in vivo tend to be small and dynamic in migrating cells; however, highly elongated adhesions have also been observed (Harunaga and Yamada 2011; Kubow and Horwitz 2011).

The cytoskeleton in turn regulates adhesions via an incompletely understood feedback loop involving actin polymerization and myosin-II-mediated contraction (Fig. 2). Nascent adhesions form in the region of dendritic actin, and their formation is coupled to actin polymerization (Alexandrova et al. 2008; Choi et al. 2008). At the interface of dendritic actin in the lamellipodium and the actin bundles in the adjacent lamellum, adhesions elongate along actin filament bundles (Small et al. 2002; Choi et al. 2008; Geiger and Yamada 2011; Oakes et al. 2012).
The fraction of adhesions that grow, as well as the extent of maturation, is determined at least in part by myosin II activity (Vicente-Manzanares et al. 2009; Oakes et al. 2012). Proteases such as calpain, a calcium-activated protease, mediate adhesion disassembly by acting on adhesion proteins such as talin, which link actin and integrins (Franco et al. 2004; Chan et al. 2010; Cortesio et al. 2011). The repeated direct contact between microtubule tips and adhesions and endocytosis of integrins driven by the GTPase dynamin also contribute to disassembly (Kaverina et al. 1999; Broussard et al. 2008; Ezratty et al. 2009; Gerisch et al. 2011).

The formation, dynamics, and function of adhesions are highly regulated. In migrating cells, they form in protrusions near the leading edge. In rapidly migrating, amoeboid-like cells, adhesions in protrusions are small and tend to form and turnover rapidly, making them difficult to visualize. Few, if any undergo significant maturation into large, elongated structures. Cells undergoing slower, mes-

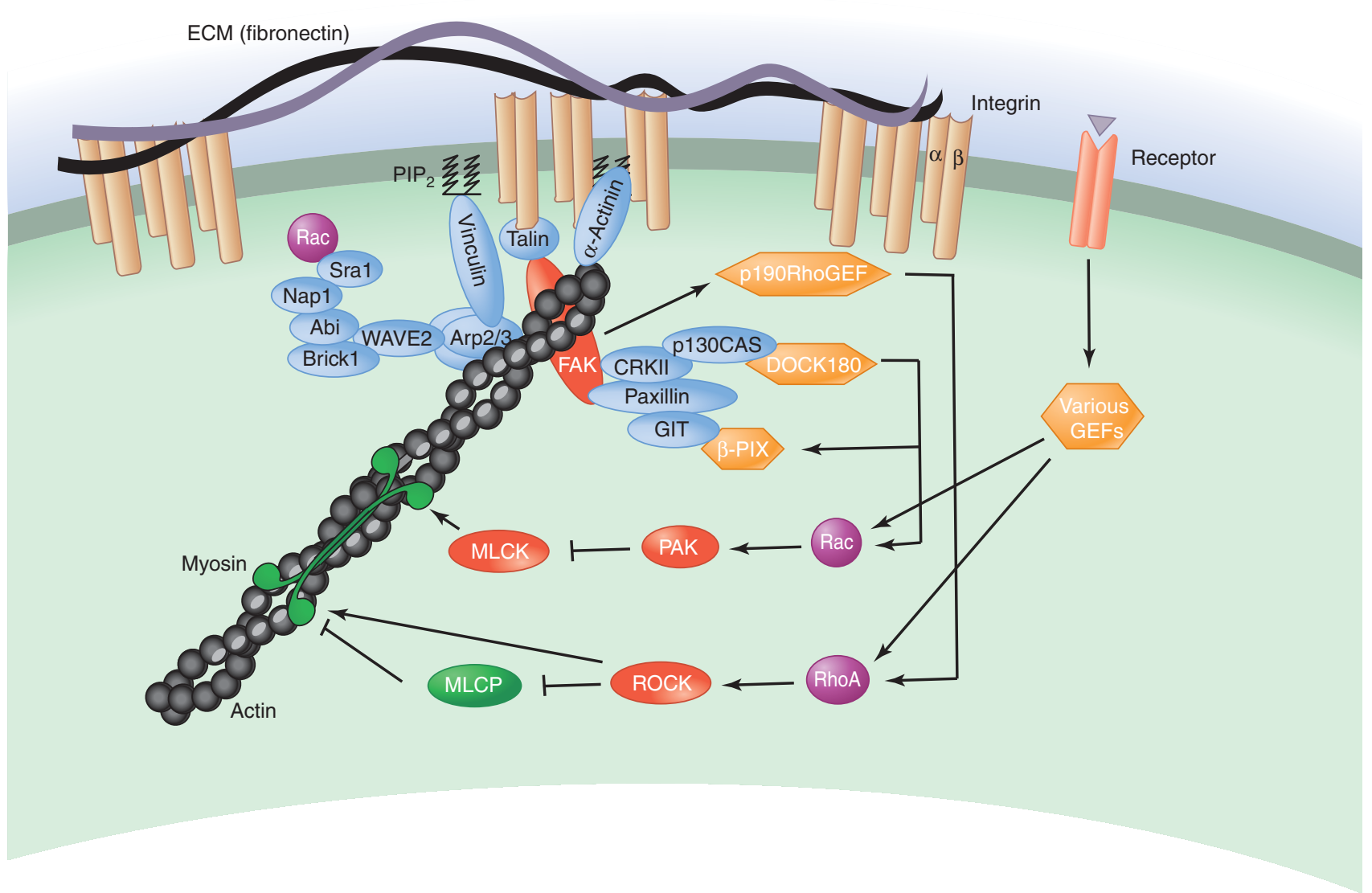

Figure 2. Adhesions serve as contact points and signaling centers. Integrin-based adhesions are large, complex assemblies that link the substratum to actin and generate signals that regulate Rho GTPases and cell migration. The structural linkage to actin is thought to be mediated by talin, vinculin, and perhaps $\alpha$-actinin. The signaling is mediated by adhesion-associated complexes. The paxillin/FAK module and its link to some Rac GEFs and Rho GEFs is shown as an example. The Arp2/3 complex and myosin II, whose activity is regulated by Rho and Rac, are also shown. 
enchymal migration tend to have larger adhesions with a significant number maturing to large, elongate adhesions (Parsons et al. 2010). These large adhesions do not appear to generate signals that drive actin polymerization.

\subsection{Polarization}

The presence of a distinct front and rear is a key feature of cell migration. Some cells can polarize spontaneously and migrate in a directionally persistent manner. The machinery that establishes polarity is incompletely understood but microtubules, vesicle cycling, and actomyosin filaments appear to be the drivers. In epithelial cells and astrocytes, polarity is established through a signaling pathway involving $\mathrm{Cdc} 42$, Par3 $/ 6$, and atypical protein kinase C (aPKC) that targets microtubules (Etienne-Manneville and Hall 2002; Etienne-Manneville et al. 2005). This pathway orients the microtubule-organizing center (MTOC) and Golgi apparatus (McCaffrey and Macara 2012). In fibroblasts, activated myosin II creates a region of actomyosin filament bundles that terminate in adhesions that do not contain guanine nucleotide exchange factors (GEFs) and therefore do not support Rac or Cdc42 signaling and actin polymerization (Vicente-Manzanares et al. 2008, 2011). This region becomes the rear and sides, and zones of active Rac generate protrusions that elongate the cell to form the front; the actomyosin system appears to set up the initial polarity, which is then refined by the microtubule system (Vicente-Manzanares et al. 2008).

\section{MIGRATION SIGNALING NETWORKS}

A complex signaling network regulates the cytoskeleton and adhesion in the context of migration. Below, we focus on Rho GTPases, integrins, and phosphoinositides, which have been extensively investigated, although it is clear that Ras proteins, calcium, cyclic nucleotides, numerous kinases, and other components are also involved. These networks contain positive- and negative-feedback loops, redundancies, and points of crosstalk often involving synergy between adhesions, chemotactic receptors, and growth factor receptors. We speculate below on the different roles of these signaling events, which are integrated to bring about migration.

\subsection{Rho-Family GTPases Regulate Cytoskeletal Activity}

Rho-family small GTPases are a major convergence point of migration-associated signaling (Heasman and Ridley 2008). Protrusion, adhesion, and polarization are all regulated by Rho-family GTPases, and many receptor-initiated signaling pathways link to the Rho GTPases (Ridley et al.
2003; Zaidel-Bar et al. 2007; Parsons et al. 2010). These include chemokine receptors and growth factor receptors, such as the epidermal growth factor (EGF) receptor. The response depends on the spatial and temporal segregation of the activities of the different GTPases and involves multiple, parallel, redundant, and synergistic pathways that form a complex network.

The pathways involved regulate Rho GTPase activity by acting on the many GEFs and GTPase-activating proteins (GAPs) that control their activity (Etienne-Manneville and Hall 2002; DerMardirossian and Bokoch 2005). The GTPases are also regulated by Rho GDP dissociation inhibitors (GDIs), which remove them from the membrane (Garcia-Mata et al. 2011). The Rho family has several members, whose functions, in the context of migration, are represented by Rac, RhoA, and Cdc42. These act on a number of effectors that control the cytoskeletal machinery (see above) (Ridley 2006, 2011; Heasman and Ridley 2008). For example, Rac and Cdc42 regulate actin polymerization by acting on the WASP family and consequently Arp $2 / 3$ : Cdc42 regulates $\mathrm{mDia} 2$, and Rac regulates cofilin through LIMK (Ridley 2011). RhoA also regulates actin polymerization by acting on mDial. In addition, it regulates adhesion and actin organization via myosin II activity: RhoA activates ROCK, which phosphorylates the myosin RLC and inhibits myosin phosphatase, both of which stimulate myosin II. Cdc42 also regulates microtubule dynamics, which in turn affects the turnover of some adhesions (Kraynov et al. 2000; Nalbant et al. 2004; Machacek et al. 2009). The front-back polarity required for migration requires that actin polymerization localizes to specific cellular regions (i.e., the leading edge of migrating cells). This is reflected in the polarized activity of Rac and Cdc42 and the intricate relative kinetics of their activation.

\subsection{The Paxillin/FAK Signaling Module}

In mesenchymal cells at least, Rho-family GTPases are regulated by signaling complexes that reside in adhesions; they are activated by ligation of integrins to matrix proteins such as fibronectin, whose signaling synergizes with growth factor and chemokine receptor pathways (Ridley et al. 2003). The focal adhesion kinase (FAK)/paxillin signaling module is the best-studied example. Paxillin is among the earliest molecules to enter adhesions as they form and remains present until they disassemble (Webb et al. 2004). It functions as a signaling adapter that binds to numerous molecules involved in Rho-family GTPase signaling (Brown and Turner 2004; Deakin and Turner 2008).

The amino terminus of paxillin has a series of LD regions. The first two of these include two SH2-domainbinding sites (around Y31 and Y118). They are phosphor- 
ylated by FAK and Src and bind to a number of molecules, including Crk/p130Cas, FAK/Src, and Ras GAP. The phosphatase PTP PEST binds near the carboxyl terminus of paxillin and dephosphorylates these sites. p130Cas recruits a Cas-Crk-Dock180-Elmo complex, in which Dock180 functions as a GEF that activates Rac. Two other $\mathrm{LD}$ regions of paxillin bind GIT1 and GIT2 (Turner et al. 2001; Hoefen and Berk 2006). These adapters bind to Pix, a GEF for Cdc42 and Rac (Deakin and Turner 2008). Pix also binds to the kinase PAK, a Rac effector, creating a Rac and Cdc42 activator-effector signaling module (Bokoch 2003). The p85 subunit of phosphoinositide 3-kinase (PI3K) also binds to this region of paxillin and is involved in signaling to Vav, another Rac GEF (see below) (Tybulewicz et al. 2003). This list of interactions is not exhaustive but serves to illustrate the central role of paxillin as a regulator of protrusion through its action on Rac and Cdc42. Vinculin, a tension-sensitive structural molecule implicated in the integrin-actin linkage, also binds to the LD region of paxillin (Deakin and Turner 2008).

Nearly all of these binding interactions are regulated by phosphorylation of paxillin on Y31 and Y118, which creates the two SH2-binding sites as well as inducing a major conformational change. Conformational regulation is a general theme in adhesion signaling (Parsons et al. 2010; Zaidel-Bar and Geiger 2010). Src, FAK, paxillin, and p130 Cas are all conformationally activated, at least in part, by phosphorylation events, which often serve to release an autoinhibitory state (Cohen et al. 2006; Sawada et al. 2006; Parsons et al. 2010). Tension can also activate or regulate the activities of adhesion molecules. For example, p130Cas, talin, and vinculin are all tension sensitive (Sawada et al. 2006; del Rio et al. 2009; Grashoff et al. 2010). These sensitivities are thought to regulate adhesion-generated signals (Bershadsky et al. 2003; Schwartz 2010).

FAK binds to paxillin following tyrosine phosphorylation of paxillin Y31 and Y118 (Choi et al. 2011). The phosphorylation occurs after both molecules are in nascent adhesions and appears to result from a conformational activation of paxillin, because FAK binds to the carboxyl end of paxillin. FAK also recruits molecules that regulate Rho-family GTPases, functions as a tyrosine kinase, and possesses tyrosine phosphorylation sites, most of which are phosphorylated by Src (Parsons 2003; Mitra et al. 2005; Frame et al. 2010). Activated FAK binds to Src (via its $\mathrm{SH} 2$ domain), to p130Cas (via an SH3 domain), and to a p120RasGAP-p190RhoGAP complex, which negatively regulates RhoA activity. FAK binds to two Rho GEFs, p190RhoGEF and PDZRhoGEF, which activate RhoA (Tomar and Schlaepfer 2009). p190RhoGEF and p190RhoGAP do not appear to bind to FAK at the same time, and in spreading cells, binding of p190RhoGAP precedes that of
p190RhoGEF. This provides a potential mechanism for the transient, local and sequential activation of RhoA seen at the leading edge of migrating cells. Thus, RhoA activity appears to be controlled by antagonistic regulators that interact with FAK. In addition, the activity of p190RhoGAP, for example, depends on phosphorylation, which suggests that the GAPs (and probably the GEFs) are regulated by phosphorylation (Tomar and Schlaepfer 2009).

\subsection{Other Rho-Regulating Modules}

The Pax/FAK model reveals the importance and function of signaling complexes that localize the activity of Rhofamily GTPases; but other complexes do this as well. For example, the ILK-pinch-parvin complex is another adhesion-associated system that signals to Rac. The pseudokinase scaffold protein ILK binds to parvin, which binds to Pix (Sepulveda et al. 2005; Legate et al. 2006). The SH2/ $\mathrm{SH} 3$ adapter NCK is also implicated in Rac signaling in adhesions (Ruusala and Aspenstrom 2008). Finally, note that Rho-family GTPases are regulated by their association with the plasma membrane. They are targeted to lipid rafts and regulated by phosphorylation-dependent interactions with Rho GDI and endocytic events, which thereby regulate their activity (Grande-Garcia et al. 2005).

\subsection{The PI3K Signaling Module}

The PI3K signaling module (Hemmings and Restuccia 2012) acts dynamically at the leading edge of the cell to regulate the accumulation of phosphatidylinositol 3,4,5trisphosphate $\left(\mathrm{PIP}_{3}\right)$ and in turn cytoskeletal activities. The links between $\mathrm{PIP}_{3}$ and the cytoskeleton are a subject of intense investigation. $\mathrm{PIP}_{3}$ targets include substrates of Akt, including PAK, as well as a series of $\mathrm{PH}$-domain-containing proteins (Kamimura et al. 2008; Tang et al. 2011). In randomly migrating cells, patches of $\mathrm{PIP}_{3}$ are generated spontaneously and appear at the tips of protrusions. In cells migrating in gradients of chemoattractants such as chemokines or growth factors, receptors and $G$ proteins are distributed uniformly around the cell perimeter. However, $\mathrm{PIP}_{3}$ accumulation as well as other signaling events are dynamically localized at the tips of pseudopodia at the front (Parent and Devreotes 1999). PIP 3 accumulates at the leading edge of the pseudopodia because, in Dictyostelium at least, PI3K is recruited to, and PTEN (a $3^{\prime}$ specific phosphatase that hydrolyzes $\mathrm{PIP}_{3}$ ) is lost from, these regions (Funamoto et al. 2002; Iijima and Devreotes 2002; Arai et al. 2010). In neutrophils, the $5^{\prime}$-phosphatase Ship1 also degrades PIP $_{3}$ (Nishio et al. 2007; Mondal et al. 2012). 
Asymmetric $\mathrm{PIP}_{3}$ accumulation has been conserved throughout evolution in migrating cells and also operates where cells undergo related morphological changes (Fig. 3)-for example, in the extending membranes of neuronal growth cones (Wang et al. 2002; Lacalle et al. 2004; Chadborn et al. 2006; Evans and Falke 2007; Yoo et al. 2010), during cytokinesis (a process which resembles two cells migrating away from each other) (Janetopoulos et al. 2005; Janetopoulos and Devreotes 2006), in phagocytosis (Clarke et al. 2006), and in mammary and prostate epithelia (in which the basal lateral and apical portions of stationary cells are akin to the front and rear of a migrating cell, $\mathrm{PIP}_{3}$ being localized to the basal-lateral region and PTEN being localized to the apical region [Shewan et al. 2011]).

It is now clear that the asymmetrical accumulation of $\mathrm{PIP}_{3}$ is sufficient to promote actin polymerization and produce cellular projections; but it is one of a number of parallel pathways. Alterations in $\mathrm{PIP}_{3}$ levels lead to defects in cell migration, cytokinesis, phagocytosis, and epithelial architecture. In Dictyostelium cells lacking PTEN or neutrophils lacking Ship1, for example, excessive amounts of $\mathrm{PIP}_{3}$ are generated at the front of the cell and this diffuses

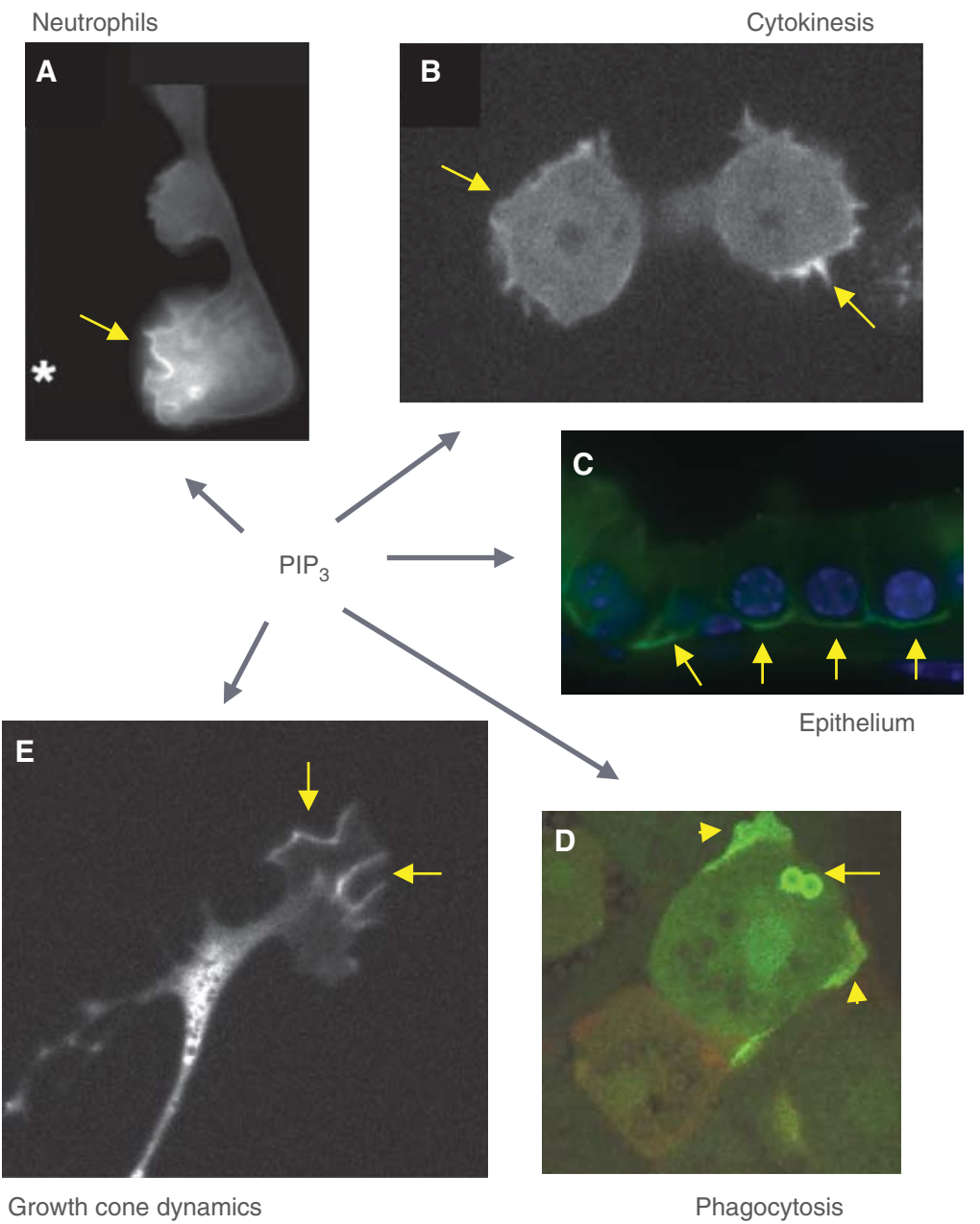

Figure 3. Asymmetric accumulation of $\mathrm{PIP}_{3}$ is a feature of a spectrum of cell morphological changes. Panels show snapshots of the dynamic distribution of $\mathrm{PIP}_{3}$ in cells undergoing various morphological changes. $(A)$ Human neutrophils expressing a biosensor for $\mathrm{PIP}_{3}$ (PHakt-GFP). The cells have been exposed to a gradient formed by a micropipette filled with the chemoattractant $\mathrm{C} 5 \mathrm{a}$ ( position indicted by ${ }^{*}$ ). The arrow shows recruitment of PHaktGFP to the membrane, indicating an elevated level of $\mathrm{PIP}_{3}$. (B) A dividing Dictyostelium cell expressing PHCrac-GFP as a biosensor for $\mathrm{PIP}_{3}$. Arrows point to the accumulation of $\mathrm{PIP}_{3}$ at the poles of the dividing cell. $(C)$ Prostate epithelial cells expressing PHakt-GFP. (Image courtesy of Tamara Lotan.) Arrows point to the accumulation of PIP 3 on the basal-lateral membranes. (D) Dictyostelium cell expressing PHCrac-GFP phagocytizing latex beads. The arrow indicates accumulation of $\mathrm{PIP}_{3}$ around two beads; arrowheads point to $\mathrm{PIP}_{3}$-labeled pseudopods in the same cell. (Image courtesy of Margaret Clarke.) (E) The growth cone of rat dorsal root ganglion expressing PHakt-GFP. Arrows indicate the accumulation of $\mathrm{PIP}_{3}$ at the leading edge. (Image courtesy of Britta Eickholt.) 
along most of the cell perimeter (Funamoto et al. 2002; Iijima and Devreotes 2002; Nishio et al. 2007). This additional $\mathrm{PIP}_{3}$ elicits ectopic pseudopodia at lateral regions outside the leading edge. If the PTEN-deficient cells are treated with inhibitors of PI3K, the morphological defects are suppressed, and the cells again display a single anterior pseudopod (Chen et al. 2003). Using a synthetic PI3K activation system in neutrophils, Inoue and Meyers showed that elevation of $\mathrm{PIP}_{3}$ alone is sufficient to initiate pseudopodial extensions (Inoue and Meyer 2008). However, because asymmetrical generation of $\mathrm{PIP}_{3}$ is only one of several parallel pathways, it is not essential for a directional response. Inhibition of PI3K blocks migration in zebrafish neutrophils and fibroblasts and random migration in Dictyostelium but, under certain conditions, does not block chemoattractant-driven migration in amoebae or human neutrophils (Chen et al. 2003; Ferguson et al. 2007; Hoeller and Kay 2007). Furthermore, primordial germ cells in zebrafish have persistent, uniformly distributed membrane $\mathrm{PIP}_{3}$ levels even as they migrate directionally (Dumstrei et al. 2004). These observations confirm that there are parallel pathways that allow cells to receive directional cues from chemoattractant receptors in the absence of $\mathrm{PIP}_{3}$.

\subsection{Genetic Analysis of a Signaling Network}

The multiple parallel pathways that drive migration form a complex network of coordinated events that are triggered by chemoattractants but can also occur spontaneously as cells migrate. A successful explanation of cell migration has to integrate the information from initially independent studies of pathways believed to directly regulate the cytoskeleton, such as those involving Rho GTPases, with others thought to transduce signals from receptors, such as PI3K signaling. Interestingly, an emerging theme is that downstream and upstream events are probably linked through multiple feedback loops.

Genetic analyses in Dictyostelium have implicated about 95 nonlethal genes in chemotaxis and about 40 can be organized into an internally consistent "wiring diagram" (Swaney et al. 2010). Some of the major features of the network include the presence of parallel pathways defined by cyclic GMP, myosin heavy-chain kinase (MHCK), the kinase Tor complex 2 (TorC2), PIP $_{3}$, and phospholipase A2 (PLA2) (Veltman et al. 2008). Four isoforms of the small G protein Ras are activated by chemoattractant and seem to act early in these pathways (Kae et al. 2004; Sasaki and Firtel 2009). A portion of the network involving PIP3 and TorC2 is examined in more detail below. Interestingly TorC2 is defined by subunits Pianissimo and Rip3. These highly conserved genes were first identified as causing chemotaxis defects in Dictyostelium and later renamed as Rictor and
Sin1, respectively (see Laplante and Sabatini 2012). Remarkably, the basic elements of this network appear to be conserved in human neutrophils, although further analysis of each pathway is needed. Similarities include the rapid activation of $\mathrm{K}-, \mathrm{H}-$, and N-Ras by chemoattractants, localization of $\mathrm{PIP}_{3}$ at the leading edge of the cell, and the critical role for mTorC2 (Bokoch 2003; Van Keymeulen et al. 2006; Liu and Parent 2011). One apparent difference is that a role for cyclic GMP has not been described in neutrophils.

There is a spatiotemporal pattern to many elements of the network. Biosensors for activation/formation/recruitment of Ras, PI3K, PIP 3 , HSPC300 (a subunit of the WAVE complex), and LimE (an actin-binding protein) serve as dynamic markers for the front of the cell whereas others, such as PTEN and myosin, define the back. The front markers reside in the cytosol, but as protrusions form they are recruited to the tips of pseudopodia (Van Haastert and Devreotes 2004). In contrast, the back markers reside uniformly in the cortex and dissociate from regions where protrusions form (Funamoto et al. 2002; Iijima and Devreotes 2002; Robinson and Spudich 2004). For example, a biosensor for the collective activation of Ras proteins (the Ras-binding domain of the kinase Raf fused to GFP) moves to protrusions at the leading edge of a migrating cell, whereas PTEN-GFP falls off. When cells are stimulated with a uniform chemoattractant, all of the front components are recruited from the cytosol to the cell periphery, whereas the back components fall off and move to the cytosol (Swaney et al. 2010). These changes are transient and the components reestablish their original locations within a few minutes.

Examining a small portion of the network involving $\mathrm{PIP}_{3}$ and TorC2 in detail reveals how genetic analyses have helped delineate signaling mechanisms involved in cell migration (Fig. 4). As outlined above, cells with elevated PIP ${ }_{3}$ levels owing to loss of PTEN display a "migration" phenotype in which ectopic protrusions form over most of the cell perimeter. This can be reversed by disrupting the Akt ortholog PKBA (Tang et al. 2011). Interestingly, the cells lacking both PTEN and PKBA have elevated PIP ${ }_{3}$ levels around the perimeter but still respond effectively to chemotactic cAMP gradients. Parallel pathways must therefore mediate the directional response despite the uniform $\mathrm{PIP}_{3}$ distribution. One of these involves a second PKB isoform, PKBR1, which can be activated independently of $\mathrm{PIP}_{3}$; unlike Akt and PKBA, PKBR1 lacks a PH domain and is instead tethered to the membrane by myristoylation (Kamimura et al. 2008). The activation of PKBR1 is mediated by phosphorylation of a hydrophobic motif by TorC2. Phosphorylation of serines/threonines within conserved hydrophobic motifs in the carboxy-terminal region of 


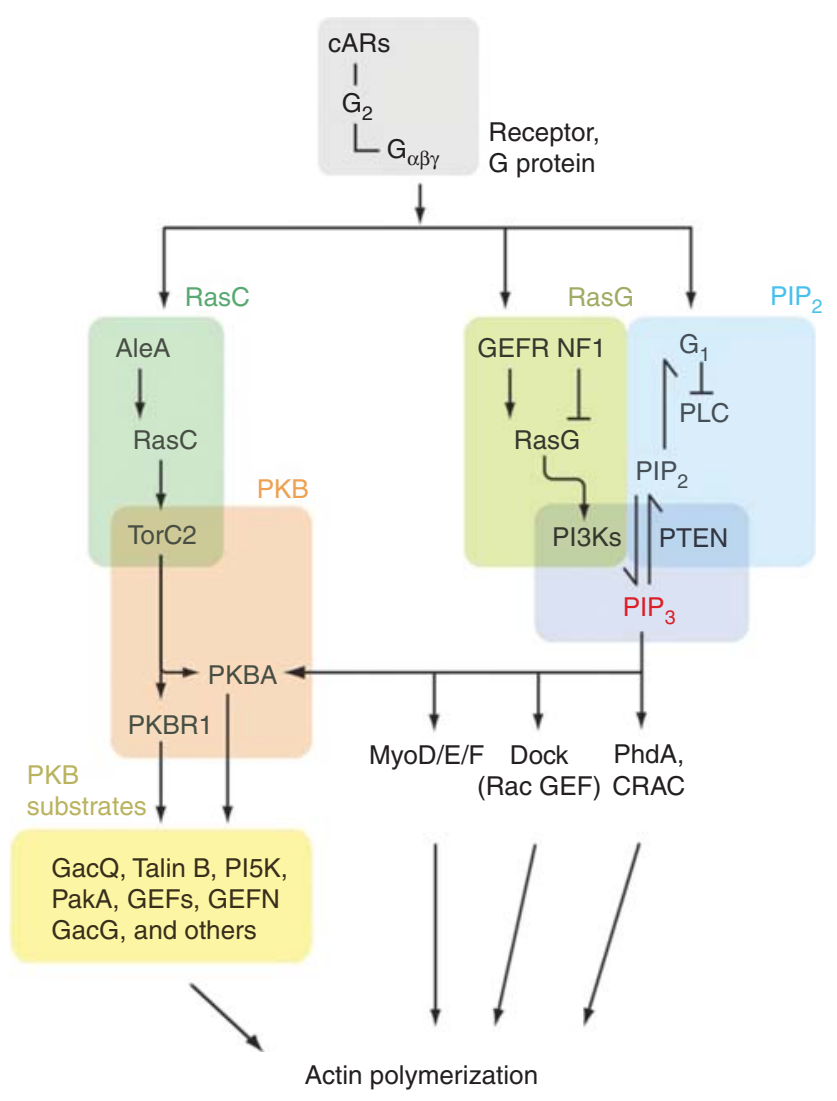

Figure 4. A portion of the Dictyostelium migration signaling network involving $\mathrm{PIP}_{3}$ and TorC2. Colored blocks delineate modules. The overlapping of blocks indicates that some components belong to several modules. CARE, cystic AMP receptors.

many ACG-family kinases (which included PKA, PKC, and PKG) can be required for their action. The phosphorylation of PKBR1 is part of a pathway that leads from chemoattractant-mediated activation of Ras through TorC2 to regulation of the cytoskeleton (Chen et al. 1997; Lee et al. 2005; Cai et al. 2010). In cells lacking RasC or Aimless, a Ras GEF for RasC, TorC2 activation is greatly reduced, whereas in cells expressing a constitutively active RasC (Q62L), TorC2 activation is elevated and ectopic sites of actin polymerization appear around the cell perimeter. However, in cells lacking Pianissimo, a key subunit of TorC2, there is no effect of expressing RasC Q62L and no phosphorylation of PKBR1. These studies focus attention on PKB substrates. In Dictyostelium, there are at least nine substrates that are rapidly, transiently phosphorylated in response to chemoattractant. These include signaling and cytoskeletal proteins, such as Ras GEFs and Rac GAPs, talin, PakA, and phosphatidylinositol 5-kinase (PI5K) (Kamimura et al. 2008).

The $\mathrm{PIP}_{3}$-independent role of TorC2 is another example of an element of the network that is conserved in neutrophils. Neutrophils lacking PI3K or exposed to PI3K inhibitors migrate along chemoattractant gradients when plated on certain extracellular matrices (Ferguson et al. 2007). Knocking down the Rictor subunit of mTorC2 causes a severe defect in neutrophil chemotaxis (Liu et al. 2010; Wang, pers. comm.). Although Akt is a substrate of mTorC2 in neutrophils, other targets are probably more important. Because PKC and other ACG kinases are phosphorylated on their hydrophobic motifs, it is possible that the mTorC2 targets are these kinases in neutrophils and other cells.

\section{BIASED EXCITABLE BIOCHEMICAL NETWORKS IN CHEMOTAXIS}

\subsection{Excitability of Signaling Networks Linked to Migration}

The signaling network controlling cell migration displays behavior, including oscillations and cortical wave propagation, which suggest the system is excitable. Excitability typically arises when a system contains opposing positive- and negative-feedback loops. These systems are in a resting state until a threshold is crossed and an all-or-nothing response ensues. Total internal reflection microscopy (TIRF) reveals that subunits of the WAVE complex and actin-binding proteins participate in wavelike phenomena that propagate along the basal surface of the cell. When these waves reach the edge of the cell, they appear to push the perimeter outward. Essentially similar phenomena are observed in human neutrophils and Dictyostelium amoebae (Gerisch et al. 2004, 2011; Weiner et al. 2007; Bretschneider et al. 2009; Gerisch 2010). Actin and integrin waves have also been observed in fibroblasts (Giannone et al. 2004; Döbereiner et al. 2006; Case and Waterman 2011). The waves form in the absence of stimulation and in mutants lacking $G$ proteins, indicating that this is an intrinsic behavior of motile cells. Furthermore, activation of Ras and accumulation of $\mathrm{PIP}_{3}$ also occur in flashes and bursting waves, which are propagated across the cortex (Arai et al. 2010; Xiong et al. 2010).

These waves can be modeled mathematically, like action potentials in neurons (Levine et al. 2006; Insall and Machesky 2009; Xiong et al. 2010; Hecht et al. 2011), by linking components of a hypothetical network in positive- and negative-feedback loops. Some feedback loops have been described in the real network. For example, a positive-feedback loop appears to link cytoskeletal events and PIP $_{3}$ because inhibition of either reduces the spontaneous activation of the other (Weiner et al. 2002; Inoue and Meyer 2008). Second, a negative-feedback loop involving the phosphorylation of upstream Ras GEF by downstream PKB has been described in Dictyostelium (Charest et al. 2010). 
Cell migration may thus involve a mechanism in which guidance cues differentially alter the excitability of the network on one side of the cell. That is, if a cue decreases the threshold for excitability on the side of the cell closer to the source and increases the threshold on the distal side, the cell will be attracted to it. Such theoretical models are referred to as biased excitable networks (BENs). Because they are typically excitable within very narrow parameter ranges, BENs can provide extreme sensitivity to external signals (Iglesias and Devreotes 2012). This mechanism may explain how professional chemotactic cells such as leukocytes and Dictyostelium are able to move up gradients of chemoattractant that differ by $<2 \%$ over their body length.

\subsection{Adaptation to Chemotactic Signaling and Local Excitation-Global Inhibition Models}

The influence of an external signal on a BEN can depend on the absolute or relative amount of the signal. The chemotactic response of $3 \mathrm{~T} 3$ fibroblasts to platelet-derived growth factor (PDGF), for example, depends on the absolute concentration and diminishes as the concentration increases and the fractional difference in receptor occupancy across the cell decreases (Schneider and Haugh 2006). In contrast, responses to chemoattractants that signal via GPCRs, such as FMLP in human leukocytes or cAMP in Dictyostelium, depend primarily on the relative steepness rather than the absolute concentration of the gradient (Devreotes and Zigmond 1988). The "relative" systems can maintain sensitivity over a wide range of concentrations.

Studies of cells treated with inhibitors of the cytoskeleton, which allow the direction-sensing system to be examined in isolation, have shown these receptors produce rapid but transient signaling events, such as $\mathrm{PIP}_{3}$ accumulation and Ras activation. Further responses can only be elicited if the stimulus is increased or removed and then reapplied (i.e., the cells adapt when receptor occupancy is held constant). In contrast, when cells are exposed to a chemotactic gradient, the biosensors form a crescent toward the high side. The crescent is maintained persistently at steady state but can immediately adjust if the chemoattractant gradient is shifted to a new direction. How do they adapt to uniform stimuli yet respond persistently to a gradient? The differential response to uniform versus gradient stimuli can be explained by local excitation-global inhibition (LEGI) models (Fig. 5) (Parent and Devreotes 1999; Janetopoulos et al. 2004; Levine et al. 2006). In a LEGI model, an increase in receptor occupancy triggers a rapid excitatory process, such as the dissociation of G-protein subunits, and a slower inhibitory process that balances excitation. Whenever excitation exceeds inhibition, a response regulator is generated; when inhibition catches up with excitation, the response regulator returns to its basal level. Because excitation is local, whereas the inhibitor is more global, in a gradient there is a persistent deflection of the response regulator above and below its basal level at the front and back of the cell, respectively.

The LEGI model is a useful conceptual device that allows one to predict the response to any combination of applied temporal and spatial stimuli, but further studies are needed to define the underlying biochemical events and to link the model to cell migration. First, the excitatory process likely corresponds to G-protein activation. When cells are exposed to chemoattractant, the G-protein subunits dissociate within a few seconds and all of the biochemical responses in the network are triggered. During the next several minutes, the responses gradually subside even though the $G$ protein does not reassociate. The mechanism that offsets the activity of the G-protein and causes the responses to subside remains to be determined. Second, LEGI schemes can account for all of the behavior of immobilized cells but fail to explain migration or polarity. However, the output of LEGI could enhance excitability at the front and suppress it at the rear (Xiong et al. 2010). This would ensure that the system responds to the steepness of a gradient but is independent of its midpoint concentration. LEGI-BEN schemes are capable of extraordinary sensitivity, and computer simulations show that this model can produce realistic temporal and spatial chemotactic responses.

\section{CONCLUDING REMARKS}

Many of the principles described in this article appear to be general and apply to cellular behaviors analogous to migration. For example, dendritic spines, small extensions along dendrites of neurons in the central nervous system, contain a highly organized postsynaptic density that receives excitatory signals. Like protrusions in migrating cells, dendritic spines are highly dynamic, they undergo complex morphologic changes, and they contain a highly organized adhesion associated with the postsynaptic density. Actin polymerization and actomyosin activity play a major role in spine and postsynaptic density (PSD) organization (Oertner and Matus 2005; Hodges et al. 2011). Rho-family GTPases have emerged as major regulators of spine organization and dynamics and are implicated in human cognitive diseases. Indeed, mutations in regulators of Rhofamily GTPases are implicated in spine-related diseases including autism, schizophrenia, and nonsyndromic mental retardation. With respect to the latter, $\alpha$-Pix (a Rac GEF), PAK3 (a Rac/Cd42 effector), and oligphrenin 1 (a Rho GAP) are all associated with nonsyndromic mental retardation in humans - a disease characterized by spine defects (van Galen and Ramakers 2005). Pix and PAK are localized 
A
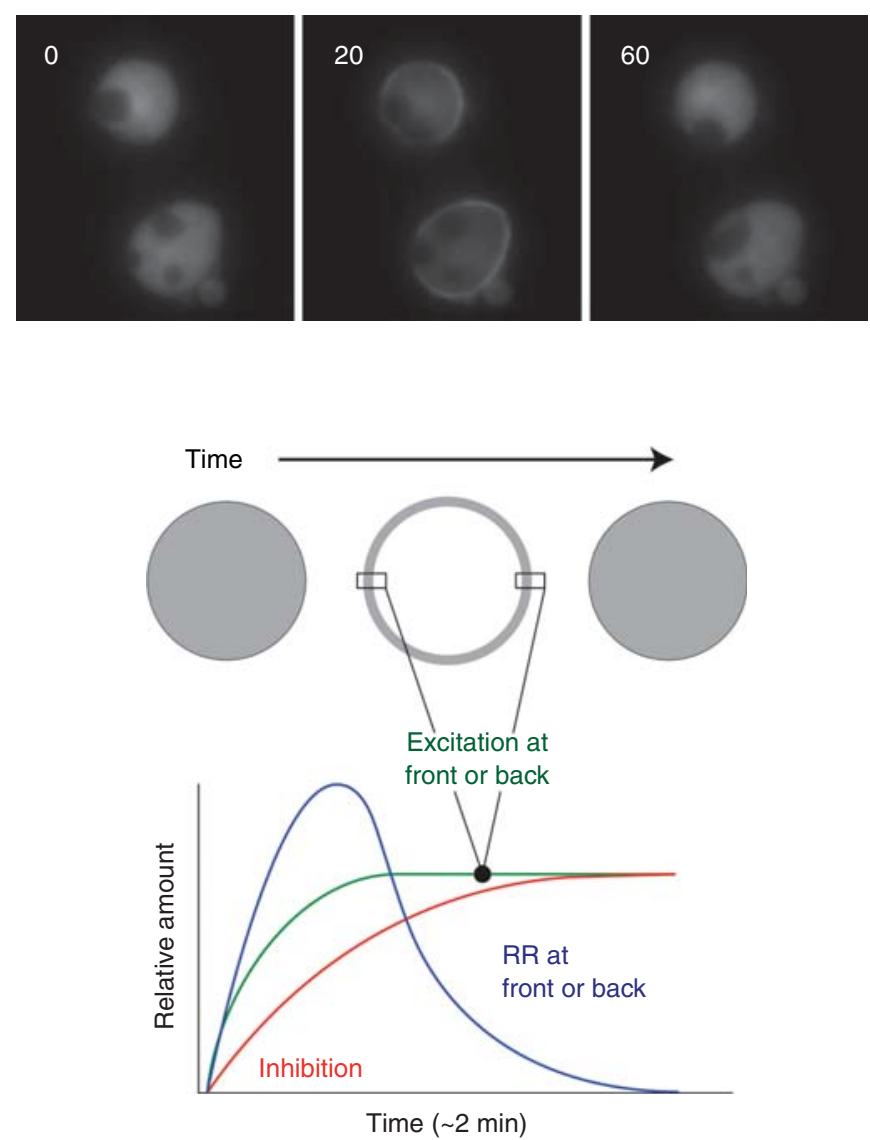

B

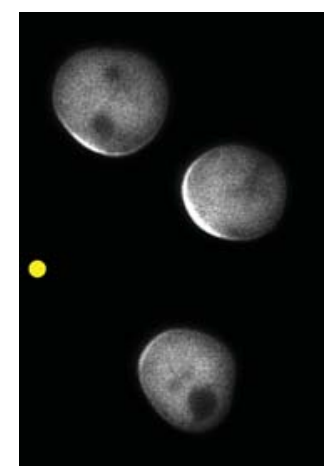

Gradient

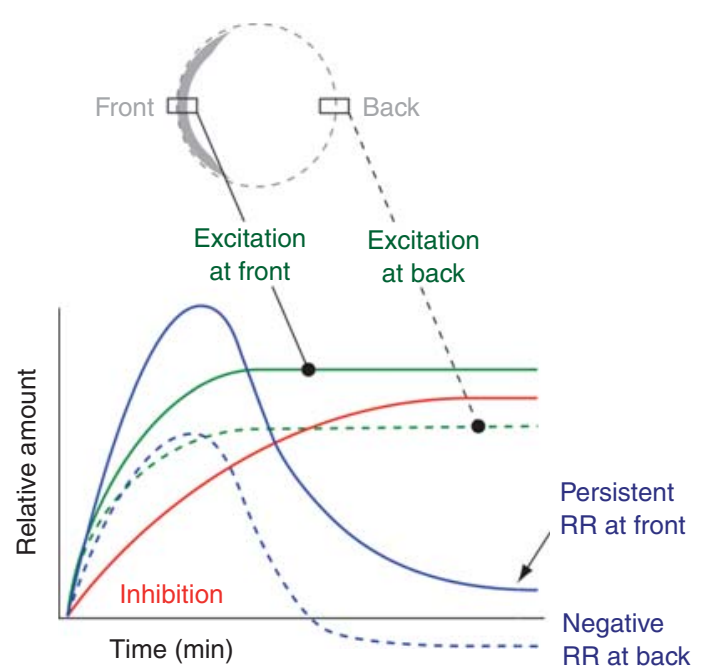

Figure 5. Responses to uniform increases and gradients of chemoattractants in a LEGI model. $(A)$ Micrographs show translocation of a biosensor for $\mathrm{PIP}_{3}$ (PHCrac-GFP) to the membrane. $\mathrm{PIP}_{3}$ levels rise transiently during persistent stimulation with a uniform chemoattractant. The schematic depicts the response of a "front" marker such as $\mathrm{PIP}_{3}$ to uniform stimulation. A LEGI model assumes that the level of a response regulator is controlled by the difference between rapid excitatory and slower inhibitory processes. The response regulator ( $R R$, blue line) rises when excitation (green line) is higher than inhibition (red line) and then falls as inhibition catches up. (B) The micrograph shows that the steady-state accumulation of $\mathrm{PIP}_{3}$ forms a crescent facing the high side of the gradient produced by a micropipette releasing chemoattractant. The schematic depicts the behavior of a "front" marker such as PIP $_{3}$ in response to a gradient of chemoattractant. In the LEGI model, the response regulator (blue line) rises when excitation (green line) is higher than inhibition (red line) and then falls to a new steady state. Because inhibition is more global than the excitation the differences generate a response regulator that has a higher concentration than basal at the front and a lower concentration than basal at the back.

to dendritic spines via GIT1 and thought to spatially restrict their formation (Zhang et al. 2005). Asymmetric localization of $\mathrm{PIP}_{3}$ is observed in many migrating cells. Oncogenic mutations leading to overproduction of $\mathrm{PIP}_{3}$ are typically assumed to increase growth rates; but it is likely that many of the cancer-causing effects can also be attributed to alterations in the cytoskeleton (Kim et al. 2011). Distortion of cell migration signaling networks plays a critical role in migration-related diseases such as invasive and metastatic cancer (Sever and Brugge 2014). The pleth- ora of signaling pathways that converge on Rho GTPases means there is a very large potential set of loci for the misregulation of migration. It also suggests that drugs directed against any particular pathway may not be effective for long given the selection that occurs in the tumor environment. However, the convergence on Rho-family GTPases and the limited migration machinery on which it acts hold promise for therapeutic strategies targeting these GTPases and their downstream effectors or diagnostic routes to identifying cells with invasive potential. 
Another emerging area of research is the study of migration in $3 \mathrm{D}$. Until recently, most migration studies focused on migration on planar substrates using integrinmediated adhesion. Analogous mechanisms are probably used by cells migrating in 3D, or using other receptors (e.g., in the central nervous system). However, different pathways might play more prominent roles in each case. For example, in $3 \mathrm{D}$, cell protrusions, adhesion, and cell morphology all appear to differ from that generally seen on rigid planar 2D substrates (Even-Ram and Yamada 2005; Provenzano et al. 2009; Friedl and Wolf 2010; Sanz-Moreno and Marshall 2010). In 3D, the cells are more elongated and possess narrower protrusions and smaller adhesions (Harunaga and Yamada 2011). Moreover, there is evidence that different signaling pathways are indeed involved. For example, depleting paxillin produces a mesenchymal phenotype in 3D environments, whereas depleting the paxillin relative Hic5 produces an amoeboid morphology (Deakin and Turner 2008, 2011). The particular signaling pathway used seems to depend on the cellular microenvironment, which can differ between normal and tumor cells.

Research into cell migration has clearly made enormous progress. The basic machines that drive migration have been described, and many of the pathways that regulate them have been identified. However, we have only scratched the surface and much remains to be understood. The interactions and regulation of the complex signaling networks that orchestrate migration and the mechanism by which extracellular forces affect these networks are not understood. Furthermore, new modes of migration are being uncovered, including blebbing-mediated migration and the newly described lobopodia migration (Petrie et al. 2012). In addition, migration in complex in vivo environments differs from that seen on rigid planar substrates and its study presents unexpected challenges. Finally, integrative, quantitative models of migration that conjoin the plethora of regulatory networks are only now beginning to be developed.

\section{REFERENCES}

\section{* Reference is also in this collection.}

Alexandrova AY, Arnold K, Schaub S, Vasiliev JM, Meister JJ, Bershadsky AD, Verkhovsky AB. 2008. Comparative dynamics of retrograde actin flow and focal adhesions: Formation of nascent adhesions triggers transition from fast to slow flow. PLoS ONE 3: e3234.

Arai Y, Shibata T, Matsuoka S, Sato MJ, Yanagida T, Ueda M. 2010. Self-organization of the phosphatidylinositol lipids signaling system for random cell migration. Proc Natl Acad Sci 107: 1239912404.

Bamburg JR, Bernstein BW. 2008. ADF/cofilin. Curr Biol 18: R273R275.

Bear JE, Gertler FB. 2009. Ena/VASP: Towards resolving a pointed controversy at the barbed end. J Cell Sci 122: 1947-1953.
Bershadsky AD, Balaban NQ, Geiger B. 2003. Adhesion-dependent cell mechanosensitivity. Annu Rev Cell Dev Biol 19: 677-695.

Bokoch GM. 1995. Chemoattractant signaling and leukocyte activation. Blood 86: 1649-1660.

Bokoch GM. 2003. Biology of the p21-activated kinases. Annu Rev Biochem 72: 743-781.

Bretschneider T, Anderson K, Ecke M, Muller-Taubenberger A, SchrothDiez B, Ishikawa-Ankerhold HC, Gerisch G. 2009. The three-dimensional dynamics of actin waves, a model of cytoskeletal self-organization. Biophys J 96: 2888-2900.

Broussard JA, Webb DJ, Kaverina I. 2008. Asymmetric focal adhesion disassembly in motile cells. Curr Opin Cell Biol 20: 85-90.

Brown MC, Turner CE. 2004. Paxillin: Adapting to change. Physiol Rev 84: $1315-1339$.

Brown CM, Hebert B, Kolin DL, Zareno J, Whitmore L, Horwitz AR, Wiseman PW. 2006. Probing the integrin-actin linkage using highresolution protein velocity mapping. J Cell Sci 119: 5204-5214.

Bugyi B, Carlier MF. 2010. Control of actin filament treadmilling in cell motility. Annu Rev Biophys 39: 449-470.

Cai H, Das S, Kamimura Y, Comer FI, Parent DA, Devreotes PN. 2010. Ras-mediated activation and inactivation of the TorC2-PKB pathway are critical for chemotaxis. J Cell Biol 190: 233-245.

Case LB, Waterman CM. 2011. Adhesive F-actin waves: A novel integrinmediated adhesion complex coupled to ventral actin polymerization. PLoS ONE 6: e26631.

Chadborn NH, Ahmed AI, Holt MR, Prinjha R, Dunn GA, Jones GE, Eickholt BJ. 2006. PTEN couples Sema3A signalling to growth cone collapse. J Cell Sci 119: 951-957.

Chan KT, Bennin DA, Huttenlocher A. 2010. Regulation of adhesion dynamics by calpain-mediated proteolysis of focal adhesion kinase (FAK). J Biol Chem 285: 11418-11426.

Charest PG, Shen Z, Lakoduk A, Sasaki AT, Briggs SP, Firtel RA. 2010. A Ras signaling complex controls the RasC-TORC2 pathway and directed cell migration. Dev Cell 18: 737-749.

Charras G, Paluch E. 2008. Blebs lead the way: How to migrate without lamellipodia. Nat Rev Mol Cell Biol 9: 730-736.

Chen M-Y, Long Y, Devreotes PN. 1997. A novel cytosolic regulator, Pianissimo, is required for chemoattractant receptor and G proteinmediated activation of the twelve transmembrane domain adenylyl cyclase in Dictyostelium. Genes Dev 11: 3218-3231.

Chen L, Janetopoulos C, Huang YE, Iijima M, Borleis J, Devreotes PN. 2003. Two phases of actin polymerization display different dependences on $\mathrm{PI}(3,4,5) \mathrm{P}_{3}$ accumulation and have unique roles during chemotaxis. Mol Biol Cell 14: 5028-5037.

Chen L, Iijima M, Tang M, Landree MA, Huang YE, Xiong Y, Iglesias PA, Devreotes PN. 2007. PLA 2 and PI3K/PTEN pathways act in parallel to mediate chemotaxis. Dev Cell 12: 603-614.

Chen L, Vicente-Manzanares M, Potvin-Trottier L, Wiseman PW, Horwitz AR. 2012. The integrin-ligand interaction regulates adhesion and migration through a molecular clutch. PLoS ONE 7: e40202.

Chesarone MA, DuPage AG, Goode BL. 2010. Unleashing formins to remodel the actin and microtubule cytoskeletons. Nat Rev Mol Cell Biol 11: 62-74.

Choi CK, Vicente-Manzanares M, Zareno J, Whitmore LA, Mogilner A, Horwitz AR. 2008. Actin and $\alpha$-actinin orchestrate the assembly and maturation of nascent adhesions in a myosin II motor-independent manner. Nat Cell Biol 10: 1039-1050.

Choi CK, Zareno J, Digman MA, Gratton E, Horwitz AR. 2011. Crosscorrelated fluctuation analysis reveals phosphorylation-regulated paxillin-FAK complexes in nascent adhesions. Biophys J 100: 583-592.

Clarke M, Muller-Taubenberger A, Anderson KI, Engel U, Gerisch G. 2006. Mechanically induced actin-mediated rocketing of phagosomes. Mol Biol Cell 17: 4866-4875.

Cohen DM, Kutscher B, Chen H, Murphy DB, Craig SW. 2006. A conformational switch in vinculin drives formation and dynamics of a talin-vinculin complex at focal adhesions. J Biol Chem 281: 1600616015 . 
Comer FI, Parent CA. 2007. Phosphoinositides specify polarity during epithelial organ development. Cell 128: 239-240.

Condeelis J. 2001. How is actin polymerization nucleated in vivo? Trends Cell Biol 11: 288-293.

Cortesio CL, Boateng LR, Piazza TM, Bennin DA, Huttenlocher A. 2011. Calpain-mediated proteolysis of paxillin negatively regulates focal adhesion dynamics and cell migration. J Biol Chem 286: 9998-10006.

Deakin NO, Turner CE. 2008. Paxillin comes of age. J Cell Sci 121: 24352444.

Deakin NO, Turner CE. 2011. Distinct roles for paxillin and Hic-5 in regulating breast cancer cell morphology, invasion, and metastasis. Mol Biol Cell 22: 327-341.

del Rio A, Perez-Jimenez R, Liu R, Roca-Cusachs P, Fernandez JM, Sheetz MP. 2009. Stretching single talin rod molecules activates vinculin binding. Science 323: 638-641.

DerMardirossian C, Bokoch GM. 2005. GDIs: Central regulatory molecules in Rho GTPase activation. Trends Cell Biol 15: 356-363.

Devreotes P, Janetopoulos C. 2003. Eukaryotic chemotaxis: Distinctions between directional sensing and polarization. J Biol Chem 278: 2044520448.

Devreotes PN, Zigmond SH. 1988. Chemotaxis in eucaryotic cells: A focus on leukocytes and Dictyostelium. Ann Rev Cell Biol 4: 649-686.

Döbereiner HG, Dubin-Thaler BJ, Hofman JM, Xenias HS, Sims TN, Giannone G, Dustin ML, Wiggins CH, Sheetz MP. 2006. Lateral membrane waves constitute a universal dynamic pattern of motile cells. Phys Rev Lett 97: 038102.

Dumstrei K, Mennecke R, Raz E. 2004. Signaling pathways controlling primordial germ cell migration in zebrafish. J Cell Sci 117: 4787-4795.

Etienne-Manneville S. 2004. Cdc42-The centre of polarity. J Cell Sci 117: $1291-1300$.

Etienne-Manneville S, Hall A. 2002. Rho GTPases in cell biology. Nature 420: 629-635.

Etienne-Manneville S, Hall A. 2003. Cell polarity: Par6, aPKC and cytoskeletal crosstalk. Curr Opin Cell Biol 15: 67-72.

Etienne-Manneville S, Manneville JB, Nicholls S, Ferenczi MA, Hall A. 2005. Cdc42 and Par6-PKCל regulate the spatially localized association of Dlg1 and APC to control cell polarization. J Cell Biol 170: 895-901.

Evans JH, Falke JJ. 2007. $\mathrm{Ca}^{2+}$ influx is an essential component of the positive-feedback loop that maintains leading-edge structure and activity in macrophages. Proc Natl Acad Sci 104: 16176-16181.

Even-Ram S, Yamada KM. 2005. Cell migration in 3D matrix. Curr Opin Cell Biol 17: 524-532.

Ezratty EJ, Partridge MA, Gundersen GG. 2005. Microtubule-induced focal adhesion disassembly is mediated by dynamin and focal adhesion kinase. Nat Cell Biol 7: 581-590.

Ezratty EJ, Bertaux C, Marcantonio EE, Gundersen GG. 2009. Clathrin mediates integrin endocytosis for focal adhesion disassembly in migrating cells. J Cell Biol 187: 733-747.

Fackler OT, Grosse R. 2008. Cell motility through plasma membrane blebbing. J Cell Biol 181: 879-884.

Ferguson GJ, Milne L, Kulkarni S, Sasaki T, Walker S, Andrews S, Crabbe T, Finan P, Jones G, Jackson S, et al. 2007. PI(3)K $\gamma$ has an important context-dependent role in neutrophil chemokinesis. Nat Cell Biol 9: $86-91$.

Frame MC, Patel H, Serrels B, Lietha D, Eck MJ. 2010. The FERM domain: Organizing the structure and function of FAK. Nat Rev Mol Cell Biol 11: 802-814.

Franco SJ, Rodgers MA, Perrin BJ, Han J, Bennin DA, Critchley DR, Huttenlocher A. 2004. Calpain-mediated proteolysis of talin regulates adhesion dynamics. Nat Cell Biol 6: 977-983.

Friedl P, Alexander S. 2011. Cancer invasion and the microenvironment: Plasticity and reciprocity. Cell 147: 992-1009.

Friedl P, Gilmour D. 2009. Collective cell migration in morphogenesis, regeneration and cancer. Nat Rev Mol Cell Biol 10: 445-457.
Friedl P, Wolf K. 2010. Plasticity of cell migration: A multiscale tuning model. J Cell Biol 188: 11-19.

Funamoto S, Meili R, Lee S, Parry L, Firtel RA. 2002. Spatial and temporal regulation of 3-phosphoinositides by PI 3-kinase and PTEN mediates chemotaxis. Cell 109: 611-623.

Garcia-Mata R, Boulter E, Burridge K. 2011. The “invisible hand": Regulation of Rho GTPases by Rho GDIs. Nat Rev Mol Cell Biol 12: 493-504.

Geiger B, Yamada KM. 2011. Molecular architecture and function of matrix adhesions. Cold Spring Harb Perspect Biol 3: a005033.

Geraldo S, Gordon-Weeks PR. 2009. Cytoskeletal dynamics in growthcone steering. J Cell Sci 122: 3595-3604.

Gerisch G. 2010. Self-organizing actin waves that simulate phagocytic cup structures. PMC Biophys 3: 7.

Gerisch G, Bretschneider T, Müller-Taubenberger A, Simmeth E, Ecke M, Diez S, Anderson K. 2004. Mobile actin clusters and traveling waves in cells recovering from actin depolymerization. Biophys $J$ 87: $3493-$ 3503.

Gerisch G, Ecke M, Wischnewski D, Schroth-Diez B. 2011. Different modes of state transitions determine pattern in the Phosphatidylinositide-Actin system. BMC Cell Biol 12: 42.

Giannone G, Dubin-Thaler BJ, Döbereiner HG, Kieffer N, Bresnick AR, Sheetz MP. 2004. Periodic lamellipodial contractions correlate with rearward actin waves. Cell 116: 431-443.

Goode BL, Eck MJ. 2007. Mechanism and function of formins in the control of actin assembly. Annu Rev Biochem 76: 593-627.

Grande-Garcia A, Echarri A, Del Pozo MA. 2005. Integrin regulation of membrane domain trafficking and Rac targeting. Biochem Soc Trans 33: 609-613.

Grashoff C, Hoffman BD, Brenner MD, Zhou R, Parsons M, Yang MT, McLean MA, Sligar SG, Chen CS, Ha T, et al. 2010. Measuring mechanical tension across vinculin reveals regulation of focal adhesion dynamics. Nature 466: 263-266.

Harunaga JS, Yamada KM. 2011. Cell-matrix adhesions in 3D. Matrix Biol 30: 363-368.

Heasman SJ, Ridley AJ. 2008. Mammalian Rho GTPases: New insights into their functions from in vivo studies. Nat Rev Mol Cell Biol 9: 690701.

Hecht I, Skoge ML, Charest PG, Ben-Jacob E, Firtel RA, Loomis WF, Levine H, Rappel WJ. 2011. Activated membrane patches guide chemotactic cell motility. PLoS Comput Biol 7: e1002044.

* Hemmings BA, Restuccia DF. 2012. PI3K-PKB/Akt pathway. Cold Spring Harb Perspect Biol 4: a011189.

Hodges JL, Newell-Litwa K, Asmussen H, Vicente-Manzanares M, Horwitz AR. 2011. Myosin IIb activity and phosphorylation status determines dendritic spine and post-synaptic density morphology. PLoS ONE 6: e24149.

Hoefen RJ, Berk BC. 2006. The multifunctional GIT family of proteins. J Cell Sci 119: 1469-1475.

Hoeller O, Kay RR. 2007. Chemotaxis in the absence of PIP3 gradients. Curr Biol 17: 813-817.

Hu K, Ji L, Applegate KT, Danuser G, Waterman-Storer CM. 2007. Differential transmission of actin motion within focal adhesions. Science 315: $111-115$.

Huang YE, Iijima M, Parent CA, Funamoto S, Firtel RA, Devreotes P. 2003. Receptor-mediated regulation of PI3Ks confines PI(3,4,5)P3 to the leading edge of chemotaxing cells. Mol Biol Cell 14: 1913-1922.

Huttenlocher A, Horwitz AR. 2011. Integrins in cell migration. Cold Spring Harb Perspect Biol 3: a005074.

Huttenlocher A, Palecek SP, Lu Q, Zhang W, Mellgren RL, Lauffenburger DA, Ginsberg MH, Horwitz AF. 1997. Regulation of cell migration by the calcium-dependent protease calpain. J Biol Chem 272: 3271932722 .

Hynes RO. 2002. Integrins: Bidirectional, allosteric signaling machines. Cell 110: 673-687. 
Iglesias PA, Devreotes PN. 2012. Biased excitable networks: How cells direct motion in response to gradients. Curr Opin Cell Biol 757: 451-468.

Iglesias PA, Levchenko A. 2002. Modeling the cell's guidance system. Sci STKE 2002: re12.

Iijima M, Devreotes PN. 2002. Tumor suppressor PTEN mediates sensing of chemoattractant gradients. Cell 109: 599-610.

Inoue T, Meyer T. 2008. Synthetic activation of endogenous PI3K and Rac identifies an AND-gate switch for cell polarization and migration. PLOS ONE 3: e3068.

Insall RH, Machesky LM. 2009. Actin dynamics at the leading edge: From simple machinery to complex networks. Dev Cell 17: 310-322.

Janetopoulos C, Devreotes PN. 2006. Phosphoinositide signaling plays a key role in cytokinesis. J Cell Biol 174: 485-490.

Janetopoulos C, Ma L, Iglesias PA, Devreotes PN. 2004. Chemoattractant-induced temporal and spatial $\mathrm{PI}(3,4,5) \mathrm{P}_{3}$ accumulation is controlled by a local excitation, global inhibition mechanism. Proc Natl Acad Sci 101: 8951-8956.

Janetopoulos C, Borleis J, Vazquez F, Iijima M, Devreotes P. 2005. Temporal and spatial regulation of phosphoinositide signaling mediates cytokinesis. Dev Cell 8: 467-477.

Jay DG. 2000. The clutch hypothesis revisited: Ascribing the roles of actin-associated proteins in filopodial protrusion in the nerve growth cone. J Neurobiol 44: 114-125.

Kae H, Lim CJ, Spiegelman GB, Weeks G. 2004. Chemoattractants-induced Ras activation during Dictyostelium aggregation. EMBO Rep 5: $602-606$.

Kamimura Y, Xiong Y, Iglesias PA, Hoeller O, Bolourani P, Devreotes PN. 2008. PIP3-independent activation of TorC2 and PKB at the cell's leading edge mediates chemotaxis. Curr Biol 18: 1034-1043.

Kaverina I, Krylyshkina O, Small JV. 1999. Microtubule targeting of substrate contacts promotes their relaxation and dissociation. J Cell Biol 146: 1033-1044.

Kim EK, Yun SJ, HA JM, Kim YW, Jin IH, Yun J, Shin HK, Song SH, Kim JH, Lee JS, et al. 2011. Selective activation of Akt1 by mammalian target of rapamycin complex 2 regulates cancer cell migration, invasion, and metastasis. Oncogene 30: 2954-2963.

Krause M, Dent EW, Bear JE, Loureiro JJ, Gertler FB. 2003. Ena/VASP proteins: Regulators of the actin cytoskeleton and cell migration. Annu Rev Cell Dev Biol 19: 541-564.

Kraynov VS, Chamberlain C, Bokoch GM, Schwartz MA, Slabaugh S, Hahn KM. 2000. Localized Rac activation dynamics visualized in living cells. Science 290: 333-337.

Kubow KE, Horwitz AR. 2011. Reducing background fluorescence reveals adhesions in 3D matrices. Nat Cell Biol 13: 3-5.

Lacalle RA, Gómez-Moutón C, Barber DF, Jiménez-Baranda S, Mira E, Martínez-A C, Carrera AC, Mañes S. 2004. PTEN regulates motility but not directionality during leukocyte chemotaxis. J Cell Sci 117: $6207-6215$.

* Laplante M, Sabatini DM. 2012. mTOR signaling. Cold Spring Harb Perspect Biol 4: a011593.

Lauffenburger DA, Horwitz AF. 1996. Cell migration: A physically integrated molecular process. Cell 84: 359-369.

Lee S, Comer FI, Sasaki A, McLeod IX, Duong Y, Okumura K, Yates JR 3rd, Parent CA, Firtel RA. 2005. TOR complex 2 integrates cell movement during chemotaxis and signal relay in Dictyostelium. Mol Biol Cell 16: $4572-4583$.

Legate KR, Montañez E, Kudlacek O, Fässler R. 2006. ILK, PINCH and parvin: The tIPP of integrin signalling. Nat Rev Mol Cell Biol 7: 20-31.

Levine H, Kessler DA, Rappel WJ. 2006. Directional sensing in eukaryotic chemotaxis: A balanced inactivation model. Proc Natl Acad Sci 103: 9761-9766.

Linder S, Wiesner C, Himmel M. 2011. Degrading devices: Invadosomes in proteolytic cell invasion. Annu Rev Cell Dev Biol 27: 185-211.

Liu L, Parent CA. 2011. TOR kinase complexes and cell migration. J Cell Biol 194: 815-824.
Liu L, Das S, Losert W, Parent CA. 2010. mTORC2 regulates neutrophil chemotaxis in a cAMP- and RhoA-dependent fashion. Dev Cell 19: 845-857.

Machacek M, Hodgson L, Welch C, Elliott H, Pertz O, Nalbant P, Abell A, Johnson GL, Hahn KM, Danuser G. 2009. Coordination of Rho GTPase activities during cell protrusion. Nature 461: 99-103.

* McCaffrey LM, Macara IG. 2012. Signaling pathways in cell polarity. Cold Spring Harb Perspect Biol 4: a009654.

Meili R, Ellsworth C, Lee S, Reddy TB, Ma H, Firtel RA. 1999. Chemoattractant-mediated transient activation and membrane localization of Akt/PKB is required for efficient chemotaxis to cAMP in Dictyostelium. EMBO J 18: 2092-2105.

Mitchison TJ, Cramer LP. 1996. Actin-based cell motility and cell locomotion. Cell 84: 371-379.

Mitchison T, Kirschner M. 1988. Cytoskeletal dynamics and nerve growth. Neuron 1: 761-772.

Mitra SK, Hanson DA, Schlaepfer DD. 2005. Focal adhesion kinase: In command and control of cell motility. Nat Rev Mol Cell Biol 6: $56-68$.

Mondal S, Subramanian KK, Sakai J, Bajrami B, Luo HR. 2012. Phosphoinositide lipid phosphatase SHIP1 and PTEN coordinate to regulate cell migration and adhesion. Mol Biol Cell 23: 1219-1230.

Montoya MC, Sancho D, Vicente-Manzanares M, Sánchez-Madrid F. 2002. Cell adhesion and polarity during immune interactions. Immunol Rev 186: 68-82.

Moser M, Legate KR, Zent R, Fässler R. 2009. The tail of integrins, talin, and kindlins. Science 324: 895-899.

Nalbant P, Hodgson L, Kraynov V, Toutchkine A, Hahn KM. 2004. Activation of endogenous Cdc42 visualized in living cells. Science 305: $1615-1619$.

Newey SE, Velamoor V, Govek EE, Van Aelst L. 2005. Rho GTPases, dendritic structure, and mental retardation. J Neurobiol 64: 58-74.

Nishio M, Watanabe K, Sasaki J, Taya C, Takasuga S, Iizuka R, Balla T, Yamazaki M, Watanabe H, Itoh R, et al. 2007. Control of cell polarity and motility by the PtdIns $(3,4,5) \mathrm{P} 3$ phosphatase SHIP1. Nat Cell Biol 9: $36-44$.

Oakes PW, Beckham Y, Stricker J, Gardel ML. 2012. Tension is required but not sufficient for focal adhesion maturation without a stress fiber template. Cell Biol 196: 363-374.

Oertner TG, Matus A. 2005. Calcium regulation of actin dynamics in dendritic spines. Cell Calcium 37: 477-482.

Padrick SB, Rosen MK. 2010. Physical mechanisms of signal integration by WASP family proteins. Annu Rev Biochem 79: 707-735.

Palecek SP, Loftus JC, Ginsberg MH, Lauffenburger DA, Horwitz AF. 1997. Integrin-ligand binding properties govern cell migration speed through cell-substratum adhesiveness. Nature 385: 537-540.

Parent CA, Devreotes PN. 1999. A cell's sense of direction. Science 284: $765-770$

Parent CA, Blacklock BJ, Froehlich WM, Murphy DB, Devreotes PN. 1998. G protein signaling events are activated at the leading edge of chemotactic cells. Cell 95: 81-91.

Parsons JT. 2003. Focal adhesion kinase: The first ten years. J Cell Sci 116: $1409-1416$.

Parsons JT, Horwitz AR, Schwartz MA. 2010. Cell adhesion: Integrating cytoskeletal dynamics and cellular tension. Nat Rev Mol Cell Biol 11: 633-643.

Paul AS, Pollard TD. 2009. Review of the mechanism of processive actin filament elongation by formins. Cell Motil Cytoskeleton 66: 606-617.

Petrie RJ, Gavara N, Chadwick RS, Yamada KM. 2012. Nonpolarized signaling reveals two distinct modes of 3D cell migration. J Cell Biol 197: 439-455.

Pollard TD, Borisy GG. 2003. Cellular motility driven by assembly and disassembly of actin filaments. Cell 112: 453-465.

Pollitt AY, Insall RH. 2009. WASP and SCAR/WAVE proteins: The drivers of actin assembly. J Cell Sci 122: 2575-2578. 
Ponti A, Machacek M, Gupton SL, Waterman-Storer CM, Danuser G. 2004. Two distinct actin networks drive the protrusion of migrating cells. Science 305: 1782-1786.

Provenzano PP, Eliceiri KW, Keely PJ. 2009. Shining new light on 3D cell motility and the metastatic process. Trends Cell Biol 19: 638-648.

Ridley AJ. 2006. Rho GTPases and actin dynamics in membrane protrusions and vesicle trafficking. Trends Cell Biol 16: 522-529.

Ridley AJ. 2011. Life at the leading edge. Cell 145: 1012-1022.

Ridley AJ, Schwartz MA, Burridge K, Firtel RA, Ginsberg MH, Borisy G, Parsons JT, Horwitz AR. 2003. Cell migration: Integrating signals from front to back. Science 302: 1704-1709.

Robinson DN, Spudich JA. 2004. Mechanics and regulation of cytokinesis. Curr Opin Cell Biol 16: 182-188.

Ruusala A, Aspenstrom P. 2008. The atypical Rho GTPase Wrch1 collaborates with the nonreceptor tyrosine kinases Pyk2 and Src in regulating cytoskeletal dynamics. Mol Cell Biol 28: 1802-1814.

Sasaki AT, Firtel RA. 2009. Spatiotemporal regulation of Ras-GTPases during chemotaxis. Methods Mol Biol 571: 333-348.

Sawada Y, Tamada M, Dubin-Thaler BJ, Cherniavskaya O, Sakai R, Tanaka S, Sheetz MP. 2006. Force sensing by mechanical extension of the Src family kinase substrate p130Cas. Cell 127: 1015-1026.

Schmidt S, Friedl P. 2010. Interstitial cell migration: Integrin-dependent and alternative adhesion mechanisms. Cell Tissue Res 339: 83-92.

Schneider IC, Haugh JM. 2006. Mechanisms of gradient sensing and chemotaxis: Conserved pathways, diverse regulation. Cell Cycle 5: $1130-1134$.

Schwartz MA. 2010. Integrins and extracellular matrix in mechanotransduction. Cold Spring Harb Perspect Biol 2: a005066.

Sepulveda JL, Gkretsi V, Wu C. 2005. Assembly and signaling of adhesion complexes. Curr Top Dev Biol 68: 183-225.

* Sever R, Brugge JS. 2014. Signaling in cancer. Cold Spring Harb Perspect Med doi: $10.1101 /$ cshperspect.a006098.

Shattil SJ, Kim C, Ginsberg MH. 2010. The final steps of integrin activation: The end game. Nat Rev Mol Cell Biol 11: 288-300.

Shewan A, Eastburn DJ, Mostov K. 2011. Phosphoinositides in cell architecture. Cold Spring Harb Perspect Biol doi: 10.1101/ cshperspect.a004796.

Slessareva JE, Dohlman HG. 2006. G protein signaling in yeast: New components, new connections, new compartments. Science 314: $1412-1413$.

Small JV, Resch GP. 2005. The comings and goings of actin: Coupling protrusion and retraction in cell motility. Curr Opin Cell Biol 17: $517-523$

Small JV, Stradal T, Vignal E, Rottner K. 2002. The lamellipodium: Where motility begins. Trends Cell Biol 12: 112-120.

Swaney KF, Huang CH, Devreotes PN. 2010. Eukaryotic chemotaxis: A network of signaling pathways controls motility, directional sensing, and polarity. Annu Rev Biophys 278: 20445-20448.

Takeuchi H, Higashiyama T. 2011. Attraction of tip-growing pollen tubes by the female gametophyte. Curr Opin Plant Biol 14: 614-621.

Tada T, Sheng M. 2006. Molecular mechanisms of dendritic spine morphogenesis. Curr Opin Neurobiol 16: 95-101.

Tang M, Iijima M, Kamimura Y, Chen L, Long Y, Devreotes PN. 2011a. Disruption of PKB signaling restores polarity to cells lacking tumor suppressor PTEN. Mol Biol Cell 22: 437-447.

Tang M, Iijima M, Devreotes P. 2011b. Generation of cells that ignore the effects of PIP3 on cytoskeleton. Cell Cycle 10: 2817-2818.

Tomar A, Schlaepfer DD. 2009. Focal adhesion kinase: Switching between GAPs and GEFs in the regulation of cell motility. Curr Opin Cell Biol 21: $676-683$.

Trinkaus JP. 1969. Cells into organs: The forces that shape the embryo, p. 215. Prentice-Hall, Englewood Cliffs, NJ.

Turner CE, West KA, Brown MC. 2001. Paxillin-ARF GAP signaling and the cytoskeleton. Curr Opin Cell Biol 13: 593-599.

Tybulewicz VL, Ardouin L, Prisco A, Reynolds LF. 2003. Vav1: A key signal transducer downstream of the TCR. Immunol Rev 192: 42-52. van Galen EJ, Ramakers GJ. 2005. Rho proteins, mental retardation and the neurobiological basis of intelligence. Prog Brain Res 147: 295-317.

Van Haastert PJ, Devreotes PN. 2004. Chemotaxis: Signalling the way forward. Nat Rev Mol Cell Biol 5: 626-634.

Van Keymeulen A, Wong K, Knight ZA, Govaerts C, Hahn KM, Shokat KM, Bourne HR. 2006. To stabilize neutrophil polarity, PIP3 and Cdc42 augment RhoA activity at the back as well as signals at the front. J Cell Biol 174: 437-445.

Veltman DM, Keizer-Gunnik I, Van Haastert PJ. 2008. Four key signaling pathways mediating chemotaxis in Dictyostelium discoideum. J Cell Biol 180: 747-753.

Vicente-Manzanares M, Horwitz AR. 2011. Myosin IIA/IIB restrict adhesive and protrusive signaling to generate front-back polarity in migrating cells. J Cell Biol 193: 381-396.

Vicente-Manzanares M, Sancho D, Yáñez-Mó M, Sánchez-Madrid F. 2002. The leukocyte cytoskeleton in cell migration and immune interactions. Int Rev Cytol 216: 233-289.

Vicente-Manzanares M, Koach MA, Whitmore L, Lamers ML, Horwitz AF. 2008. Segregation and activation of myosin IIB creates a rear in migrating cells. J Cell Biol 183: 543-554.

Vicente-Manzanares M, Ma X, Adelstein RS, Horwitz AR. 2009. Nonmuscle myosin II takes centre stage in cell adhesion and migration. Nat Rev Mol Cell Biol 10: 778-790.

Vicente-Manzanares M, Newell-Litwa K, Bachir AI, Whitmore LA, Horwitz AR. 2011. Myosin IIA/IIB restrict adhesive and protrusive signaling to generate front-back polarity in migrating cells. J Cell Biol 193: 381-396.

Wang Y-L. 2007. Flux at focal adhesions: Slippage clutch, mechanical gauge, or signal depot. Sci STKE 2007: e10.

Wang F, Herzmark P, Weiner OD, Srinivasan S, Servant G, Bourne HR. 2002. Lipid products of $\mathrm{PI}(3)$ Ks maintain persistent cell polarity and directed motility in neutrophils. Nature Cell Biology 4: 513-518.

Webb DJ, Donais K, Whitmore LA, Thomas SM, Turner CE, Parsons JT, Horwitz AF. 2004. FAK-Src signalling through paxillin, ERK and MLCK regulates adhesion disassembly. Nat Cell Biol 6: 154-161.

Weiner OD, Neilsen PO, Prestwich GD, Kirschner MW, Cantley LC, Bourne HR. 2002. A PtdInsP(3)- and Rho GTPase-mediated positive feedback loop regulates neutrophil polarity. Nat Cell Biol 4: 509-513.

Weiner OD, Marganski WA, Wu LF, Altschuler SJ, Kirschner MW. 2007. An actin-based wave generator organizes cell motility. PLoS Biol 5: e221.

Welch HC, Coadwell WJ, Ellson CD, Ferguson GJ, Andrews SR, Erdjument-Bromage H, Tempst P, Hawkins PT, Stephens LR. 2002. P-Rex1, a PtdIns $(3,4,5) \mathrm{P} 3$ - and $\mathrm{G} \beta \gamma$-regulated guanine-nucleotide exchange factor for Rac. Cell 108: 809-821.

Xiong Y, Huang C-H, Iglesias PA, Devreotes PN. 2010. Cells navigate with a local-excitation, global-inhibition-biased excitable network. Proc Natl Acad Sci 107: 17079-17086.

Yamaguchi H, Condeelis J. 2007. Regulation of the actin cytoskeleton in cancer cell migration and invasion. Biochim Biophys Acta 1773: 642652.

Yoo SK, Deng Q, Cavnar PJ, Wu YI, Hahn KM, Huttenlocher A. 2010. Differential regulation of protrusion and polarity by PI3K during neutrophil motility in live zebrafish. Dev Cell 18: 226-236.

Zaidel-Bar R, Geiger B. 2010. The switchable integrin adhesome. J Cell Sci 123: 1385-1388.

Zaidel-Bar R, Itzkovitz S, Ma'ayan A, Iyengar R, Geiger B. 2007a. Functional atlas of the integrin adhesome. Nat Cell Biol 9: 858-867.

Zaidel-Bar R, Milo R, Kam Z, Geiger B. 2007b. A paxillin tyrosine phosphorylation switch regulates the assembly and form of cell-matrix adhesions. J Cell Sci 120: 137-148.

Zhang H, Webb D, Asmussen J, Niu H, Horwitz AF. 2005. A GIT1/PIX/ Rac/PAK signaling module regulates spine morphogenesis and synapse formation through MLC. J Neurosci 25: 3379-3388. 


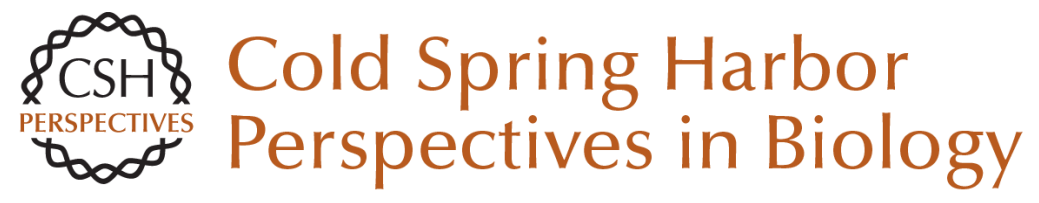

\section{Signaling Networks that Regulate Cell Migration}

Peter Devreotes and Alan Rick Horwitz

Cold Spring Harb Perspect Biol 2015; doi: 10.1101/cshperspect.a005959

Subject Collection Signal Transduction

Cell Signaling and Stress Responses Gökhan S. Hotamisligil and Roger J. Davis

Protein Regulation in Signal Transduction Michael J. Lee and Michael B. Yaffe

Synaptic Signaling in Learning and Memory Mary B. Kennedy

Vertebrate Reproduction Sally Kornbluth and Rafael Fissore

Signaling in Lymphocyte Activation Doreen Cantrell

Signaling in Muscle Contraction Ivana Y. Kuo and Barbara E. Ehrlich

Toll-Like Receptor Signaling Kian-Huat Lim and Louis M. Staudt

Signaling Pathways that Regulate Cell Division Nicholas Rhind and Paul Russell
Second Messengers

Alexandra C. Newton, Martin D. Bootman and John D. Scott

Signals and Receptors Carl-Henrik Heldin, Benson Lu, Ron Evans, et al.

Cell Death Signaling Douglas $R$. Green and Fabien Llambi

Signaling Networks that Regulate Cell Migration Peter Devreotes and Alan Rick Horwitz

Signaling Networks: Information Flow, Computation, and Decision Making Evren U. Azeloglu and Ravi lyengar

Signal Transduction: From the Atomic Age to the Post-Genomic Era Jeremy Thorner, Tony Hunter, Lewis C. Cantley, et al.

Signaling by the TGF $\beta$ Superfamily Jeffrey L. Wrana

Subversion of Cell Signaling by Pathogens Neal M. Alto and Kim Orth

For additional articles in this collection, see http://cshperspectives.cshlp.org/cgi/collection/

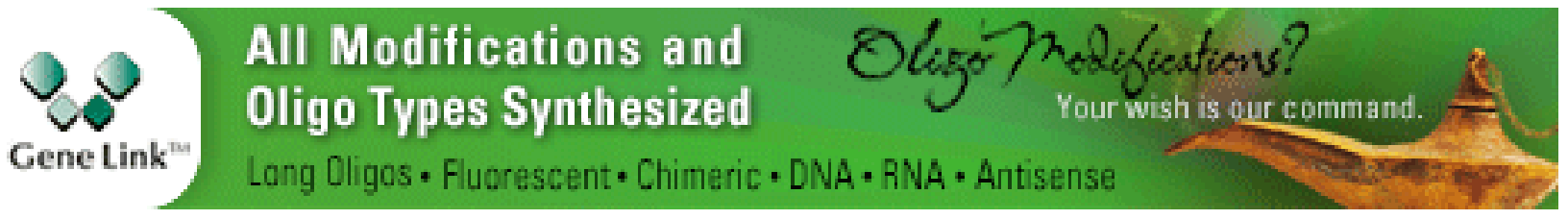

Copyright @ 2015 Cold Spring Harbor Laboratory Press; all rights reserved 